\title{
Fotografia: \\ desafios da interdisciplinaridade
}

\author{
MARIA ELIZA LINHARES BORGES*
}

\begin{abstract}
Resumo: O presente artigo toma a fotografia como ponto de partida para refletir sobre os possíveis diálogos entre dois campos de conhecimento específicos: a História Social da Cultura e a História da Arte. Além de analisar algumas das principais questões que hoje permeiam o debate relativo ao uso das representações imagéticas, sobretudo da fotografia, na História da Arte, na História da Fotografia e na Historia Social da Cultura, o artigo também identifica e discute os desafios enfrentados pelo profissional da História strictu senso na análise da composição fotográfica, cada vez mais utilizada nas pesquisas históricas.
\end{abstract}

\begin{abstract}
The present article presents the photography as a starting point to reflect upon the possible dialogs between two specific fields of knowledge: the Social History of Culture and Art History. Besides analyzing some of the key issues that permeate the debate regarding the use of imagetic representations, mainly photography, in the Art History, in the History of Photography and in the Social History of Culture, the article also identifies and discusses the challenges faced by the professional in strictu senso History when analyzing the photographic composition, which is used more and more in the historical research.
\end{abstract}

Palavras-chave: Fotografia. História da cultura. História da arte.

Key words: Photography. History of culture. History of arts.

O presente texto se propõe a refletir sobre possíveis diálogos entre dois campos de conhecimento específicos: a História Social da Cultura e a História da Arte. ${ }^{1}$ Mais que discorrer sobre os fundamentos teórico-metodológicos que apontam as conexões entre arte e sociedade - temática que fez história sobretudo a partir dos teóricos do Instituto Warburg (Burucúa, 2003) -, escolhemos pensar tais relações a partir de um lugar definido: a fotografia.

Prof ${ }^{a}{ }^{\text {Dept }}{ }^{\circ}$ de História/UFMG.

1 Esta é uma versão modificada do texto intitulado Fotografia: diálogos entre a História Social da Cultura e a História da Arte, apresentado no XXIV Colóquio do Comitê Brasileiro de História da Arte, em Belo Horizonte, em outubro de 2004.

Estudos Ibero-Americanos. PUCRS, v. XXXI, n. 2, p. 41-51, dezembro 2005 
Ter a fotografia como nosso fio condutor é uma forma de evitar os riscos inerentes às análises de cunho generalizantes que tanto poderiam diluir as especificidades da História Social da Cultura quanto as da História da Arte. Mas a pertinência de nossa abordagem também se deve a um fenômeno universal em curso desde fins do século XX: a entrada da fotografia "nas estruturas canônicas do saber e da cultura" (Fontecuberta, 2001, p. 7). Ao lado da proliferação de exposições fotográficas nas galerias de arte e nos museus, sinal da dinamização do mercado artístico da fotografia, deparamo-nos, ainda, com a multiplicação dos acervos fotográficos nos arquivos e nas bibliotecas ${ }^{2}$ destinadas à pesquisa acadêmica.

Em parte, este boom da fotografia (contemporânea e/ou histórica) é ao mesmo tempo produto e produtor da crise de paradigmas que vem tensionando e desafiando o funcionamento das $\mathrm{Ci}$ ências Sociais nas últimas décadas. A presença incontestável da fotografia nos espaços artísticos e de pesquisa é, pois, um sintoma de que sempre que jogada porta afora, ela retornava janela adentro destes mesmos territórios. Funcionando como uma anomalia, a fotografia passou a perturbar o andamento da Ciência Normal e, como diria Thomas Kuhn (1978), acabou contribuindo para a crítica de alguns dos cânones da Arte, da História da Arte e das Ciências Sociais.

No caso específico da História, pode-se dizer que tal crise incidiu, dentre outros aspectos, sobre o reconhecimento do papel desempenhado pela cultura nos diferentes âmbitos do tecido social. Foi assim que a fotografia, ao lado de outras imagens, se imiscuiu nos campos da pesquisa em História (Borges, 2003, p. 75-79). Entre os anos setenta e oitenta do século passado, as fontes imagéticas, relegadas a um plano secundário desde Tucídides, contribuíram para fertilizar os debates teórico-metodológicos responsáveis pela proposição de "novos problemas, novos objetos e novas

2 Sabe-se que a presença da fotografia nos museus antecede à crise de paradigmas tanto da História da fotografia quanto das Ciências Sociais e das Artes em geral. No século XIX, a imagem fotográfica já disputava espaço com a pintura nos diversos salões das Exposições Universais; em 1889, quando a família real brasileira deixou o país que acabava de se tornar uma República, D. Pedro II doou à Biblioteca Nacional sua extensa coleção de fotografias; antes de finda a primeira metade do século XX, mais precisamente em 1930, o MOMA, recém-inaugurado, passou a adquirir coleções de fotografias que, logo em seguida, integrariam seu Departamento de Fotografia; em 1936-7, Beaumont Newhall publicou seu hoje clássico History of photographe, resultado da coleção de fotografias deste museu. Em que pese a presença da fotografia nestes espaços culturais do século XIX, nossa intenção é chamar a atenção para o fenômeno da institucionalização da fotografia nesses mesmos espaços culturais e científicos; o que só ocorre a partir de fins do século XX. 
abordagens" aos territórios dos historiadores" (Le Goff e Nora, 1995). Movimento similar parece estar ocorrendo também no campo da História da Arte, haja vista o numero expressivo de trabalhos relacionados com a fotografia no programa deste Colóquio.

Diante de tais constatações, cabe indagar: que questões e que problemas têm norteado os debates entre aqueles que lançam mão da fotografia para refletir acerca de seus objetos de análise? Em que medida a fotografia pode ou não contribuir para a promoção do diálogo entre os historiadores da arte e os da cultura?

Sem pretender desenvolver um balanço sobre os inúmeros estudos acerca da fotografia, hoje disponíveis no mercado editorial, lembramos aqui uma obra publicada neste milênio sob a direção de Joan Fontecuberta: Fotografia. Crisis de historia. Seus dezoito artigos oferecem-nos uma idéia do debate atual sobre a História da Fotografia. Além de duvidarem da utopia de se construir uma Teoria Geral sobre a Fotografia, acabam por estimular a comunidade de acadêmicos, artistas, curadores e críticos de arte a repensarem a influência da obra de Beaumont Newhall, History of photographe de 1936, não apenas na própria historia da fotografia, mas também nas investigações científicas e na montagem de acervos fotográficos em museus e arquivos. Conforme ponderam alguns autores, se a obra de Newhall teve o mérito de construir uma "arqueologia da fotografia", também foi responsável pelo silêncio que se formou, durante anos, em torno da natureza discursiva da fotografia, das metamorfoses da percepção de suas imagens e sobretudo dos filtros culturais, ideológicos e políticos que sempre regem os modelos historiográficos dominantes, os quais, por sua vez, influenciam modos de ver e de olhar as imagens. Ao levar em conta essas e outras questões, os autores de Fotografia. Crisis de historia propõem um repensar sobre os cânones da História da Fotografia.

Na realidade, a certeza da impossibilidade de se criar uma Teoria Geral sobre a Fotografia - talvez a única existente neste campo de pesquisa - já se encontrava disseminada em inúmeros estudos publicados ao longo da década de 1990. Apenas para exemplificar, destaquemos quatro coletâneas cuja alta freqüência nas notas de rodapé de dissertações e teses de diferentes campos do saber confirmam a aceitação da natureza híbrida da fotografia. A primeira delas, intitulada: Fotografia: usos e funções no século XIX, foi organizada por Annateresa Fabris e publicada em primeira edição em 1991; a segunda, O fotográfico, a cargo de Etienne Samain, chegou ao mercado em segunda edição em 1998; a terceira nos remete ao número 27 da Revista do Patrimônio Histórico Artístico Nacional, intitulado: Fotografia, datado de 1998 e dirigido por Ma- 
ria Inez Turazzi e, finalmente, temos a coletânea organizada por Michel Frizot, La nouvelle histoire de la photographie, datada de 1994. Respeitadas suas especificidades, podemos dizer que tanto nas publicações organizadas pelos autores brasileiros, quanto na francesa, a fotografia mostra suas múltiplas faces; assume seu status de técnica, arte e documento sócio-cultural.

Como bem observa Fabris, regida pelas convenções de um novo binômio: o da automatização/criação, a fotografia subverte a tradição pictórica, calcada no par manualidade/criação. Em função disso, ela rompe com a perspectiva renascentista e instaura uma outra forma de arte (Fabris, 2000, p. 8-9). Cria, a nosso ver, uma cultura visual veloz, transitória e fragmentada, muito embora comprometida com a preservação da memória individual e coletiva.

Ainda sobre o perfil dos estudos presentes nas coletâneas acima referidas, cabe ponderar: a interdisciplinaridade construída a partir da fotografia é mais um propósito do que propriamente uma realidade. Em geral, cada analista estrutura suas reflexões dentro de seu próprio campo de estudo. Se por um lado reconhecemos a legitimidade deste procedimento por certo anti-enciclopédico, por outro, acreditamos ser hora de diminuir os silêncios, ainda grandes, existentes entre campos do saber próximos, como é o caso da Historia Social da Cultura e da História da Arte. Afinal, as questões que norteiam a prática da pesquisa de seus profissionais estão sempre a remeter a dimensões relativas a um mesmo lugar: a sociedade, com todos seus constrangimentos e todas as suas ambigüidades. Explicitemos melhor este ponto de vista.

Em A miséria da teoria, E. P. Thompson (1981) lança mão de uma metáfora com o objetivo de ressaltar a marca fundamental do trabalho histórico. Conforme nos lembra este autor, o ofício do historiador se assemelha ao de um marceneiro que deve conhecer de antemão a natureza de cada madeira a ser manuseada. $\mathrm{O}$ domínio deste saber específico é uma das pré-condições para a escolha adequada das ferramentas a serem utilizadas na operação de transformação da matéria bruta em objeto de uso e/ou de troca. A nosso ver, a analogia construída por Thompson transcende o campo específico da reflexão histórica. Para além das particularidades de cada área do conhecimento, o analista das imagens fotográficas deverá ter consciência do tipo de indagações que elas comportam. Caso contrário, sua entrada na pesquisa estará reduzida à mera ilustração. Portanto, além de investigar as condições de produção da imagem; de explicitar as redes de interesses existentes entre fotógrafo e seus possíveis patrocinadores; de conhecer os mecanismos utilizados para sua veiculação; de considerar as metamor- 
foses da percepção e da recepção; espera-se, de seu analista, clareza quanto ao tipo de convenções que regem a confecção das imagens fotográficas.

Um dos caminhos para responder a essas questões seria agregar às ponderações de Thompson as de Walter Benjamin explicitas em Uma breve história da fotografia (1931). Como seu interesse primordial era entender as especificidades do fenômeno cultural na modernidade oriunda da Revolução Industrial (Khothe, 1995, p. 14), Benjamin sugeriu que ao invés de se refletir sobre "a fotografia como arte" - debate que, segundo, ele estava em pauta desde a criação desta imagem -, os estudiosos passassem a pensar a "arte como fotografia", quer dizer, reconhecessem a arte enquanto um tipo de representação.

Seguindo seu raciocino, diríamos que para Benjamin "a construção mais ou menos artística da fotografia, que transforma a vivência em objeto a ser apropriado pela câmera" (Benjamin, 1985, p. 104) é um fenômeno da modernidade. Nele, a fotografia e o cinema têm um papel importante. Em $A$ obra de arte na era de sua reprodutibilidade técnica, o autor parece nos dar a chave para pensarmos acerca da natureza artística ou não da reprodução fotográfica. Segundo ele, se por um lado a reprodução da obra de arte é responsável por sua descontextualização, por outro, é a liberdade advinda do uso dos diferentes mecanismos de reprodutibilidade o elemento a permitir que a sociedade transforme a técnica (um artefato que em princípio aprisiona e aliena o homem) em um ato coletivo pleno de criatividade. Em outras palavras, a conjugação de dois elementos de natureza distintas: (1) o aperfeiçoamento das técnicas de reprodução de imagens e textos (a imprensa, a fotografia, o cinema e os meios virtuais, acrescentaríamos nós) e (2) a ação das metamorfoses da percepção e do olhar podem criar as condições para que as sociedades sejam invadidas por uma enxurrada de representações visuais e textuais. Este fenômeno não só incentiva a diversificação dos meios de reprodutibilidade visual e textual, como também instaura as condições para que tais reproduções sejam constantemente re-atualizadas do ponto de vista estético. $\mathrm{O}$ que Benjamin parece estar nos dizendo é que ao reproduzir uma imagem visual, total ou parcialmente, a fotografia, ou qualquer outro meio técnico, acaba por interferir na sua composição. Sempre que isso ocorre, a imagem reproduzida adquire um novo perfil; torna-se uma re-apresentação, uma re-criação da imagem ma- 
triz, agora concebida a partir das convenções culturais de seus novos consumidores. ${ }^{3}$

Ora, o leitor poderia argüir, não sem razão, que a criação presente no ato da reprodutibilidade não atingiria, por exemplo, às fotografias produzidas para documentarem e/ou testemunhar um dado fenômeno social, uma vez que aí o valor estético não é, necessariamente, um imperativo para a composição da imagem fotográfica. Para o que nos interessa, importa ressaltar que o ato de reproduzir fragmentos do real não é um processo passivo, pois o fotógrafo - seja ele independente ou atrelado a demandas públicas - age sobre o real informado por códigos sociais, políticos, ideológicos, comerciais mas também estéticos. ${ }^{4}$ Caso contrário, a "composição" da imagem produzida correria o risco de não ser compreendida por seu público-alvo. Com isso estamos chamando a atenção também para o fato de que a dimensão analógica da fotografia não faz de suas imagens uma mera reprodução do real. Mesmo porque, as imagens fotográficas são representações bidimensionais de uma realidade tridimensional. Este aspecto, por si só, insere a fotografia no universo representacional próprio dos signos visuais fixos. A visualidade por ela produzida é, a um só tempo, informada por sua gênese automática e pelos condicionamentos sócioculturais que orientam o olhar e as escolhas do fotógrafo, dos mediadores culturais responsáveis pela divulgação e distribuição das imagens e também pelo gosto e pelas demandas dos consumidores.

A nosso ver, estas são questões que fazem da fotografia uma espécie de campo aberto ao diálogo entre os estudiosos da História

3 Não estamos querendo com isso dizer que toda reprodução de obra de arte também seja uma obra de arte. Estamos tão somente chamando a atenção para o caráter representacional e inventivo da reprodução fotográfica.

4 Ao abordarmos esta questão, temos em mente uma situação muito comum nas áreas urbanas, sobretudo das grandes cidades entre fins do século XIX e início do século XX. Para ficarmos na sociedade brasileira, lembremos o caso das fotografias produzidas por Augusto Malta, fotógrafo contratado pelo prefeito da capital federal, Pereira Passos, para documentar, via fotografia, as áreas do Rio de Janeiro que seriam objeto de sua reforma urbana higienista. A maioria das imagens fotográficas produzidas por Malta era realmente destinada a convencer os empreiteiros privados e o próprio governo federal da urgência de se reformar certas áreas da capital, seja por motivos de saúde pública, seja para facilitar o trânsito de mercadorias, máquinas e pessoas. Outra parcela das fotografias produzidas teve a função de divulgar, dentro e fora do país, uma estética urbana própria da Belle Époque, quer dizer, da era do espetáculo. Algumas dessas representações fotográficas são, simultaneamente, uma celebração/monumentalização do ideal de metrópole moderna vigente sobretudo no mundo ocidental, entre fins do século XIX até a primeira Guerra Mundial, e um diálogo com a estética realista característica da pintura de paisagem. 
Social da Cultura e da História da Arte. Ambas lidam com representações. A diferença fundamental entre seus objetos está no fato de que enquanto a primeira busca compreender as verdades atribuídas às representações sociais, materiais e simbólicas; lembranos Argan que à História da Arte cabe compreender a história das obras de arte, peças fundamentais do sistema cultural (Argan e Fagiollo, 1994, p. 14). Na realidade, o trabalho de ambos historiadores pressupões seleções, cortes, recortes e ordenação de seus documentos e objetos de estudo. Tais operações se pautam nas convenções que norteiam cada um de seus ofícios. Enquanto a História strictu senso se apóia nas convenções que os atores pesquisados definem como verdadeira; a História da Arte se apóia nas convenções estéticas possibilitadas por seus contextos culturais. É nessa medida que as metodologias utilizadas pela História Social da Cultura criam zonas de diálogos com a Historia da Arte.

Pensando com Thompson e com Benjamin, diríamos que para os historiadores de ambas disciplinas o entendimento das imagens fotográficas requer clareza quanto às convenções técnicas, artísticas e culturais que as informam. Nossa vivência pessoal tem nos mostrado que os métodos de análise próprios da Historia Social da Cultura permitem saber como os fotógrafos recortam a realidade; o que dela escolhem para nos mostrar; o que silenciam; que recursos intelectuais e técnicos utilizam; que demandas e que interesses, individuais e coletivos, influenciam suas práticas. Quando indagamos onde? quando? como? por quê? com quem? e com que propósitos as representações fotográficas foram e/ou são produzidas, divulgadas e incorporadas, estamos, na realidade, contextualizando seus processos de produção, divulgação e consumo. Não é demais lembrar que o ato de contextualizar uma ou mais forma de manifestação da vida social é uma operação mais sofisticada do que pretende o discurso ordinário, o qual a concebe enquanto um exercício limitado, de um lado, pela demarcação cronológica e, de outro, pela localização geográfica do fenômeno a ser analisado. Ao contrário, a contextualização é uma operação que requer consciência dos diferentes trânsitos entre o visto e o não visto; o explícito e o implícito; entre o dito e o interdito. Sua execução pressupõe, pois, o uso de metodologias capazes de apreender o sentido que os atores/produtores de uma determinada época atribuem a seus atos e representações, bem como a análise dos recursos técnicos, estéticos e simbólicos utilizados para sua materialização.

Este tipo de orientação metodológica vem sendo utilizado por diversos historiadores e pesquisadores da história da arte. Vale lembrar aqui os estudos de Fred Orton, Griselda Pollock, 
Linda Nochlin, T. G. Clark (Harris, 2001), R. Kraus (Krauss, 2002), dentre outros. Trabalhando com os conceitos de new art history ou de radical art history, Jonathan Harris nos mostra como as análises de Clark, Pollock e Nochlin, sobretudo, distanciam-se daqueles analistas integrantes da traditonal art history. Enquanto estes se limitam a operar nos campos canônicos da historia da arte, os primeiros têm criado métodos e procedimentos investigativos capazes de problematizar temas, objetos e abordagens considerados intocáveis até meados dos anos de 1960.

Dentre as características da radical art history acham-se tanto a preocupação com as formas na Historia da Arte, quanto com a relação que elas possam vir a ter com os significados sociais e políticos dos fenômenos sociais. Além disso, os analistas inseridos nessa corrente de pensamento e pesquisa também atribuem grande importância ao lugar das mediações culturais (linguagens, idéias, valores e formas de comunicação) na produção de artefatos visuais. Para tanto, dedicam-se ao estudo de questões ligadas aos artistas (produtores) e aos diferentes tipos de intermediários responsáveis pela veiculação, critica e distribuição das obras de arte em seus respectivos mercados. Indiretamente, os museus e as galerias de arte também integram o rol de temas dos integrantes da radical art history (Harris, 2001, p. 13-17).

Além de quebrarem o monopólio dos estudos sobre "as grandes obras" e os "grandes artistas", os historiadores da radical art history incluem, no rol de suas pesquisas, temas e objetos marginalizados pela traditonal art history. Este parece ser o caso dos estudos de Griselda Pollock e Linda Nochlin que, nos anos de 1970, deram início à pesquisa sobre mulheres pintoras tanto do Renascimento quanto do século XIX. De acordo com Harris, os estudos de Nochlin mostram como as pintoras dos anos oitocentos, excluídas dos currículos de História da Arte durante muito tempo, lançavam mão de temas e técnicas não usuais entre os pintores do sexo masculino formados nas instituições artísticas do mesmo período (Nochlin, apud, Harris, 2001, p. 98-100). Na realidade, este e outros estudos de História Social da Arte estão chamando a atenção para as relações entre arte e mercado artístico; entre arte e instituições de ensino; entre arte e sistemas de patrocínio. Nessa dimensão, pode-se dizer que dialogam diretamente com as metodologias próprias da Sociologia da Cultura e da História Social da Cultura.

Indiretamente os resultados dessas investigações põem em causa as teses onde artista e obra de arte são reduzidos a ecos de suas temporalidades cronológicas (Taine, apud Argan e Fagiolo, 
1995, p. 92 e segs.); contestam aqueles que por privilegiarem a obra de arte em detrimento de seu contexto histórico, acabam por converte-la em "pura visualidade" (Wolfflin, apud Francastel,s.d., p. 311 e segs.); ou, ainda, em fruto da genialidade de seu produtor (Croce, apud Argan e Fagiolo, 1995, p. 92 e segs.). Ao que tudo indica, essa geração de historiadores da arte está atenta aos filtros políticos, ideológicos, sociais e culturais que modelam as novas e velhas culturas do olhar.

Metodologias similares também vem sendo empregadas por estudiosos da imagem fotográfica. Cada vez mais surgem análises interessadas em localizar os grandes temas do debate fotográfico produzido a partir das Sociedades Fotográficas do século XIX. A partir da década de 1860, principalmente, fotógrafos de diferentes áreas da Europa e dos Estados Unidos deram início ao movimento pictorialista destinado, segundo seus criadores, a resgatar a dimensão artística da fotografia então muito abalada por sua crescente mercantilização. Além de melhor situar espacialmente e temporalmente esse movimento ainda pouco estudado, tais pesquisas também têm tido o mérito de analisar os textos das revistas produzidas pelo movimento e de analisar a seqüência de suas exposições, nacionais e internacionais, promovidas com o intuito de revalorizar a imagem fotográfica, sobretudo o retrato. A reconstituição histórica do pictorialismo tem sido feita a partir do estudo de temas como: a natureza do debate estético no interior do movimento picotorialista; as dissidências ocorridas no seio de diversas Sociedades Fotográficas que se recusavam a aceitar a dimensão artística da fotografia; as relações entre fotógrafos e pintores; as tensões entre a fotografia artística e comercial; o papel da crítica nas exposições nacionais e internacionais promovidas pelos pictorialistas e, sobretudo, os argumentos apresentados pelos pictorialistas para inserção da fotografia no campo artístico (Scomazzon, 2004, p. 46-48; Rosemblum, 2001, p. 40-43).

No caso específico das análises que R. Krauss desenvolve sobre a fotografia, percebe-se que seu trânsito pela semiótica é orientado por um compromisso com a perspectiva histórica. Nos diferentes textos de $O$ fotográfico, Krauss tem o cuidado de reconstituir as variáveis do ambiente histórico-artístico da Belle Époque para mostrar como a idéia do espetáculo, própria do período, interferiu fortemente na elaboração de uma nova estética: a estética da exposição. Como bem observa a autora, para compreendermos a natureza das mudanças nas matrizes discursivas das imagens de uma determinada época, no caso de seus estudos, o século XIX, é importante saber localizar as relações de poder presentes no processo 
de aceitação e de rejeição de um determinado tipo de estética. Não por acaso, Krauss chamou a atenção para o lugar da crítica como um espaço de exposição, ao lado das galerias e dos museus. Segundo ela, a crítica é

um lugar de uma reação escrita perante a presença de obras em seu contexto específico e, de outro, o lugar implícito da escolha (inclusão ou exclusão), em que tudo o que é excluído do espaço de exposição acaba sendo marginalizado no plano do estatuto artístico (Krauss, 2002, p. 41).

A percepção do poder da crítica na valorização ou na marginalização de um determinado gênero artístico não é propriamente uma temática nova. Na realidade, desde os anos sessenta do século XX ela vem sendo abordada por alguns sociólogos sociólogos da cultura, como Raymond Williams e Pierre Francastel, por exemplo (Williams, 1992; Fancastel, 1970); a novidade da análise de Krauss está, exatamente, no fato dela ter centrado sua atenção na fotografia, tema não abordado por esses autores. Colocar em questão as interpretações sobre as imagens fotográficas feitas exclusivamente a partir dos critérios da linguagem pictórica é, sem dúvida, um outro mérito de seu estudo. Sem negar o diálogo entre pintura e fotografia no século XIX, Krauss convida o leitor a analisar a fotografia a partir de sua matriz discursiva que, segundo ela, é um dos principais elementos a explicar a especificidade de um determinado tipo de imagem visual. Combinados, todos essas variáveis permitem compreender o sentido atribuído a uma imagem na conjuntura em que ela é produzida e divulgada.

Para concluirmos, é preciso reconhecer, no entanto, que as metodologias da História stricto sensu e da História Social da Arte têm seus limites. Por si só, elas não permitem apreender as dimensões artísticas das obras de arte, nem tampouco esclarecem os meandros dos diálogos entre distintos gêneros estéticos. Nossa entrada recente no campo da História da Arte tem nos mostrado o quão difícil é, para um forasteiro, lidar com as matrizes discursivas das convenções artísticas; ou, ainda, apreender a composição de uma obra. Saber que a fotografia dialoga com pintura ou que ambas são produções históricas que seguem certas determinações culturais não é suficiente, por exemplo, para identificarmos onde, como e porque esses diálogos se interrompem e/ou criam uma nova e diversa estética. Mas não sejamos tão pessimistas. Transformemos as dificuldades por nós vivenciadas em desafios, em estímulos capazes de fazer crescer as fileiras daqueles que vêem na interdis- 
ciplinaridade o caminho mais fértil para a compreensão das questões e dos problemas que as sociedades nos colocam.

\section{Referências}

ARGAN, G.; FAGIOLO, M. Guia de história da arte. 2. ed. Lisboa: Estampa, 1994.

BORGES, Maria Eliza L. História \& fotografia. Belo Horizonte: Autêntica, 2003.

BURUCÚA, José Emilio. História, arte e cultura: de Aby Warburg a Carlo Ginzburg. México: Fondo de Cultura Economica, 2003.

FABRIS, Annateresa (Org.). Fotografia: usos e funções no século XIX. 2. ed. São Paulo: EDUSP, 1998.

. A História da Arte Hoje. mimeo, 2000.

FRANCASTEL, Pierre. Arte e técnica nos séculos XIX e XX. Lisboa: Ed. Livros do Brasil, s.d.

ـ Sociologia del arte. Madrid: Alianza, 1975.

FONTECUBERTA, Joan (Org.). Fotografia. Crisis de historia. Barcelona: Actar, 2001.

KRAUSS, Rosalind. O fotográfico. Barcelona: Gustavo Gilli, 2002.

KHUN, T. A estrutura das revoluções científicas. 2. ed. São Paulo: Perspectiva, 1978.

HARRIS, Jonathan. The new art history. London/New York: Routledge, 2001.

FRIZOT, Michel (Org.). La nouvelle histoire de la photographie. Paris: PUF, 2001.

LE GOFF, J.; NORA, P. História: novos problemas. 4. ed. Rio de Janeiro: Francisco Alves, 1995.

LIMA, Luciana Teixeira. Belo Horizonte dos modernistas: representações ambivalentes da cidade moderna. Belo Horizonte: C/Arte, 2004.

ROSEMBLUM, Naomi. La fotografia como arte: unos guardo retrospettivo. Fotologia - Rivista del Museo di Storia della Fotografia Fratelli Alina,. Firenze, Fratelli Alinari, n. 21-22, p. 40-43, 2001.

SAMAIN, E. (Org.). O fotográfico. 2. ed., São Paulo: Hucitec/CNPq, 1998.

SCOMAZZON, Mita. La fotografia in "Natura ed Arte". Fotostorica, Venezia, SVE, n. 27-28, p. 46-48, 2004.

THOMPSON, E. P. A miséria da teoria. Rio de Janeiro: Zahar, 1981.

TURAZZI, Maria Ines (Org.). Fotografia. Revista do Patrimônio Histórico e Artístico Nacional, Brasília, CNPq, n. 27, 1998.

WILLIAMS, Raymond. Cultura. Rio de Janeiro: Paz e Terra, 1992. 